\title{
Perioperative Monitoring and Control of Large Volume Liposuction: A Case Series Study
}

\author{
MOHAMED FATHI ABOZEID, M.D., M.R.C.S. England \\ The Department of Plastic Surgery, Faculty of Medicine, Cairo University, Egypt
}

\section{INTRODUCTION}

Over the second half of the second millennium, obesity became one of the hazards for the health of many people over the world as it increases the morbidity and mortality due to many conditions like diabetes mellitus, atherosclerosis, hypertension, and hyperlipidemia [1].

Nowadays, liposuction with its all different techniques, dry, wet, super wet and tumescent techniques, is the most commonly performed cosmetic procedures in the World for management of obesity $[2,3]$.

The definition of large volume liposuction (LVL) is the total volume removal of five liters or more including fat in addition to the wetting solution used [4-6].

Adherence to the five pillars of safety i.e. properly trained and educated surgeon in liposuction techniques, well-trained anesthesiologist, completely equipped facility, trained support staff, proper selection of the patient tends to minimize the major complications [7].

Of course, the higher the volume removed, the higher the incidence of adverse events. Thus, over the years, there was a great debate about the safety in LVL [8-11].

Because each patient has its individualized health parameters, the search for an intra-operative on-table parameter that help the surgeon detect when to stop liposuction is an important life-saving task. Thus, the rationale intended for our current study was to explore the efficiency of using the intraoperative $\mathrm{HB}$ monitoring in series as a reliable method in those patients.

\section{PATIENTS AND METHODS}

This case-series study was conducted during the period from June 2014 to July 2015 with sixmonth follow-up period in Al-Kateb Hospital and Royal Hospital, Cairo, Egypt. The goal of this study was clearly explained in the Arabic language to all subjects before their enrollment to the study, and an informed consent form was signed by and obtained from all of those enrolled.

We recruited 30 obese patients (BMI>30), between 25 to 55 years, who were willing to undergo liposuction for management of their obesity. Inclusion criteria included tight to loose skin (not redundant) and $\mathrm{Hb}$ above $12 \mathrm{mg} / \mathrm{dl}$.

Exclusion criteria included: American Society of Anesthesia score 3 or 4 (high risk for anesthesia), patients with organ failure, diabetes mellitus, and collagen vascular diseases, and patients with bleeding tendencies. Also, heavy smokers were excluded.

\section{Preoperative patient assessment:}

All patients were evaluated by detailed history, careful physical examination and photographed pre, intra and postoperative using Nikon d3200 DSLR Camera, $18-55 \mathrm{~mm}$ lens. Photography views were standard front and lateral views.

History included: Age of the patient, history of cardiac problems, liver disease, renal disease or recent drug intake. Adequate physical examination with stress on the following points was done: The general examination includes signs of renal failure or liver disease. A detailed examination was done to assess for the degree of obesity and skin redundancy. 
We explained to the patient about the idea of the operation, discussion with them to know their expectations.

\section{Laboratory investigations:}

Blood samples were taken from patients as routine preoperative preparation for complete blood picture, coagulation profile and liver and kidney functions, random blood sugar.

\section{Preoperative markings:}

With the patient standing, areas to be treated were outlined with a fibertip marking pen. Areas to be avoided or areas for fat grafting also are separately identified. Port sites per area are defined to allow cross-tunneling aspiration to minimize surface abnormalities.

\section{Preparation and positioning:}

The patient was prepared circumferentially in the torso and lower extremity because these areas can be treated without repeated prepping and repositioning. The patient's skin was painted with $10 \%$ povidone iodine solution while he or she stands next to a sterile draped operating table. At completion of the skin preparation, the patient lied on the table and was sedated or given regional anesthesia as required.

\section{Tumescent Infiltration:}

All areas to be treated were injected with large volumes of a diluted epinephrine solution until turgor of the tissues is appreciable equally on both sides. Effective vasoconstriction was achieved in about $10 \mathrm{~min}$, but the effect was more pronounced after about $20 \mathrm{~min}$. A profound and long-standing anesthesia was created at the local site. Local anesthesia lasts 6 to $10 \mathrm{~h}$ into the postoperative period, and patients rarely required additional analgesia in the first few hours after surgery.

\section{Operative technique:}

Operations in all cases were done under epidural anesthesia plus sedation. In general, the standard superwet technique was used. Our standard wetting solution consisted of 1L Ringers Lactate mixed with 1 ampule of 1: 1000 epinephrine and $25 \mathrm{~mL}$ of $1 \%$ lidocaine. We adhered to the safety limits of $35 \mathrm{mg} / \mathrm{kg}$ for lidocaine and $0.07 \mathrm{mg} / \mathrm{kg}$ of epinephrine. All fluids infiltrated or infused were warmed and a Bair-Hugger was used for body temperature regulation. Depending on the case, standard suction and/or ultrasound-assisted lipectomy was performed. Intraoperative fluid management was based on maintenance (weight of patient), vital signs, urinary output, and the extent of surgery (volume infiltrated, volume aspirated). All patients were admitted to the hospital postoperatively. The urinary catheter was kept in overnight, and their vital signs and urinary output were carefully monitored. Ambulation was started the same day of surgery and strictly encouraged. Unless indicated, patients were discharged home the next day.

\section{Intraoperative monitoring:}

Hypervolemia was monitored by heart rate and blood pressure. Anemia was monitored by noninvasive continuous measurements by the Masimo Radical-7 SpHb Station (Masimo Corporation, Irvine, CA). (Fig. 1). Electrolyte imbalance was monitored by blood gas and electrolytes.

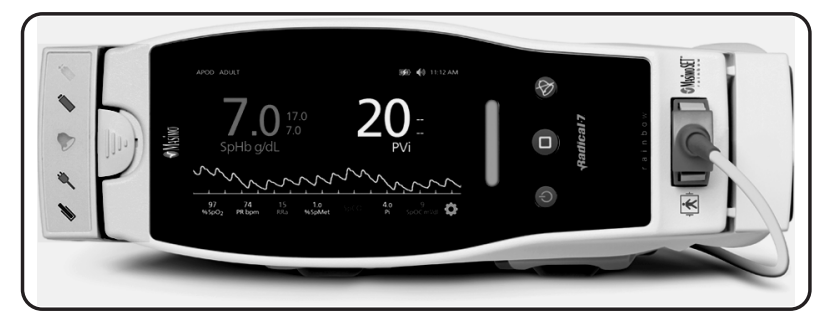

Fig. (1): Masimo Radical-7 SpHb Station.

\section{Postoperative care:}

Early ambulation, within $24 \mathrm{~h}$, was encouraged for mobilization of third-space fluid shifts to expedite recovery and to prevent deep vein thrombosis. Patients were advised to avoid prolonged sitting for 3 to 4 weeks after abdominal liposuction. Pressure garments were to be worn for up to 3 months in most instances considering the extensive mobilization of the skin panniculus in different areas. In these areas, the skin required more time to shrink to conform to the new base. It is important to support the heavy skin and subcutaneous fat of the obese patient longer than advocated to prevent it from gravitating down and forming folds. In certain cases, this period may be extended by another 3 months because skin retraction in these dissections takes longer time than with the conventional postoperative regimen. Pressure (fingertip) massage or an ultrasound massage and a further extended period of wearing thepressure garment are advised for persistent edema, pain, or firm and lumpy areas.

\section{Outcome measures:}

The primary outcome measure was to assess the intraoperative hemoglobin level reduction.

The secondary outcome measure was to quantify the postoperative hemoglobin level reduction, the shor $t$-term and long-term complications. 


\section{Statistical analysis:}

All statistical tests were done using a significance level of $95 \%$. A value of $p<0.05$ was considered statistically significant. SPSS software (Statistical Package for the Social Sciences, version 20.0, SSPS Inc, Chicago, IL, USA) was used for the statistical analyses. Data were presented as (mean $\pm \mathrm{SD}$ ) or median (range) for continuous variables and as a frequency and percent for categorical variables. Comparisons were made using the paired $t$-test for continuous variables and Chisquare test for categorical variables.

\section{RESULTS}

Baseline characteristics:

The majority of patients were female 22 (73.3\%). The age of the patients ranged from 25 to 55 years (mean age: $35.5 \pm 8.0$ ). The mean Body Mass Index was $35.8 \pm 1.5$ with a minimum of 32.9 and a maximum of $38.2 \mathrm{Kg} / \mathrm{cm}^{2}$ (Table 1 ).

Diabetes Mellitus was present in $* * \%$ of cases $(\mathrm{n}=*)$. Other risk factors included hypertension, bronchial asthma, HCV and ischemic heart $(n=*$, $*, * \& *$, respectively).

The average preoperative HB level was 13.7 (1.2) $\mathrm{g} / \mathrm{dl}$ with a minimum of 12.5 and a maximum of $17.1 \mathrm{~g} / \mathrm{dl}$.

Table (1): Baseline characteristics.

\begin{tabular}{lc}
\hline & $\begin{array}{c}\text { Mean } \pm \text { SD } \\
\text { (Min-Max) }\end{array}$ \\
\hline Age in year & $35.5 \pm 8.0(25.0-55.0)$ \\
BMI Kg/m 2 & $35.8 \pm 1.5(32.9-38.2)$ \\
\hline & Number of patients $(\%)$ \\
\hline Total number of patients & 30 \\
\hline Gender: & \\
Male & $8(26.7 \%)$ \\
Female & $22(73.3 \%)$ \\
\hline
\end{tabular}

Intraoperative and postoperative monitoring of patients:

The average amount of fat removed during the procedure was $6.3(0.9) \mathrm{L}$ with a minimum of 5.1 and a maximum of $8.4 \mathrm{~L}$. There was a highly significant positive correlation between the BMI and the amount of fat removed ( $p$-value $<0.001$ and $r=$ 0.8 ). The higher the BMI, the higher the amount of fat removed (Fig. 2).

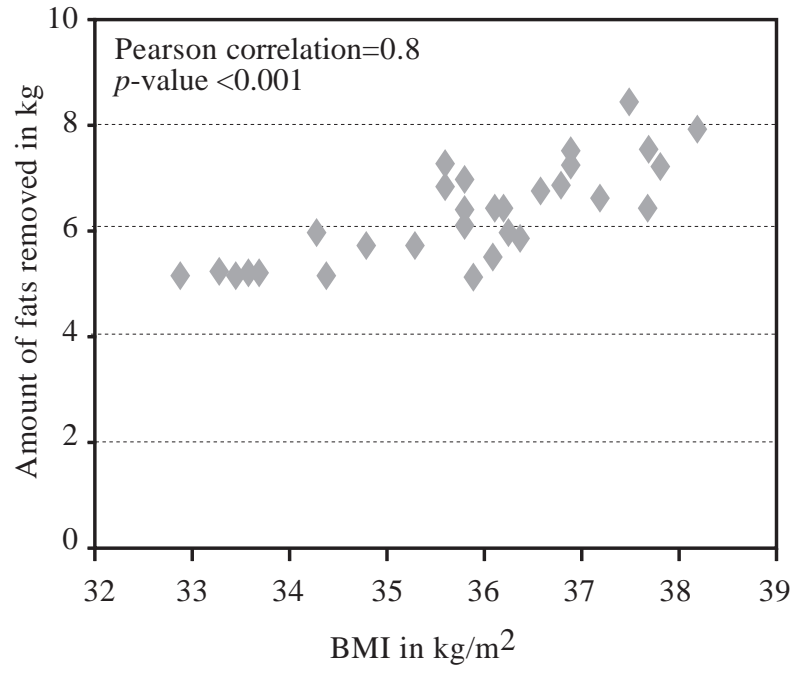

Fig. (2): Correlation between BMI and amount of fats removed.

The average intraoperative HB level was 11.8 $(1.0) \mathrm{g} / \mathrm{dl}$ with a minimum of 10.1 and a maximum of $13.9 \mathrm{~g} / \mathrm{dl}$. The average reduction in the intraoperative HB level was $1.9(0.6) \mathrm{g} / \mathrm{dl}$ with a minimum reduction of 0.9 and a maximum of $3.2 \mathrm{~g} / \mathrm{dl}$. There was a highly significant difference between the preoperative and the intraoperative HB level ( $p$ value $<0.0001$ ). There was a highly significant positive correlation between the amount of fat removed and the reduction in the intraoperative HB level ( $p$-value $<0.001$ and $r=0.8$ ). The higher the amount of fat removed, the higher the reduction in the intraoperative HB level (Table 2, Fig. 3).

Table (2): Preoperative, intraoperative and postoperative measurements.

\begin{tabular}{llll}
\hline & Mean (SD) & $\begin{array}{l}\text { (Minimum- } \\
\text { Maximum) }\end{array}$ & $p$-value \\
\hline $\begin{array}{l}\text { Amount of fats } \\
\text { removed (kg) }\end{array}$ & $6.3(0.9)$ & $(5.1-8.4)$ & \\
$\begin{array}{l}\text { HB preoperative } \\
\text { level, g/dl }\end{array}$ & $13.7(1.2)$ & $(12.5-17.1)$ & \\
$\begin{array}{l}\text { HB intraoperative } \\
\text { level, g/dl }\end{array}$ & $11.8(1)$ & $(10.1-13.9)$ & $<0.001$ \\
$\begin{array}{l}\text { HB postoperative } \\
\text { level, g/dl }\end{array}$ & $10(0.9)$ & $(8.5-12.1)$ & $<0.001$ \\
\hline $\begin{array}{l}\text { Reduction in } \\
\text { HB level } \\
\text { (preintraoperative) }\end{array}$ & $1.9(0.6)$ & $(0.9-3.2)$ & \\
$\begin{array}{l}\text { Reduction in } \\
\text { HB level } \\
\text { (prepostoperative) }\end{array}$ & $3.7(1)$ & $(2.3-7)$ & \\
\hline
\end{tabular}




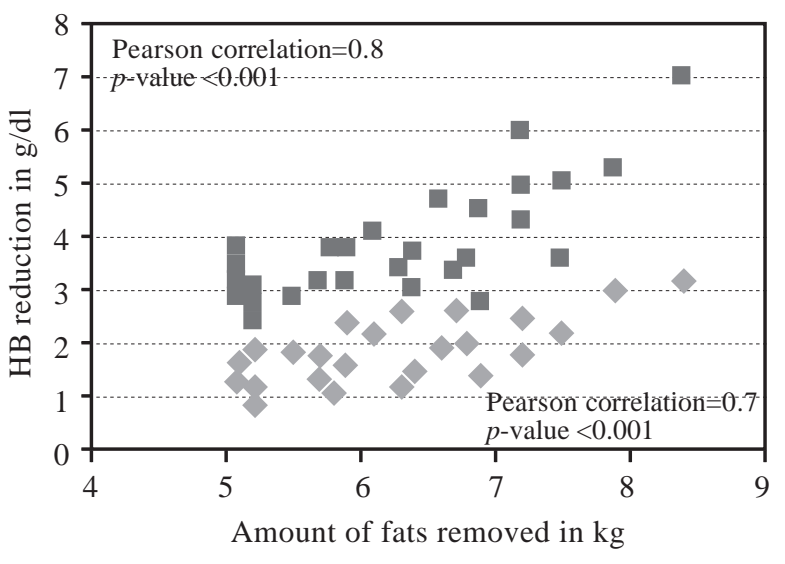

Reduction in HB level (Pre- intraoperative) Reduction in HB level (Pre- postoperative)

Fig. (3): Correlation between amount of fats removed and the reduction in $\mathrm{HB}$ level.

The average postoperative HB level was 10.0 $(0.9) \mathrm{g} / \mathrm{dl}$ with a minimum of 8.5 and a maximum of $12.1 \mathrm{~g} / \mathrm{dl}$. The average reduction in the postoperative $\mathrm{HB}$ level was 3.7 (1.0) $\mathrm{g} / \mathrm{dl}$ with a minimum reduction of 2.3 and a maximum of $7.0 \mathrm{~g} / \mathrm{dl}$. There was a highly significant difference between the preoperative and the postoperative HB level ( $p$ value $<0.0001)$. There was a highly significant positive correlation between the amount of fat removed and the reduction in the postoperative HB level ( $p$-value $<0.001$ and $r=0.7$ ). The higher the amount of fat removed, the higher the reduction in the postoperative HB level (Table 2, Fig. 3).

\section{DISCUSSION}

Since liposuction was initially introduced to the surgical community, its applications have progressively broadened from its use in small regional operations to total body contouring. The tumescent technique uses a large volume of vasoconstrictive subcutaneous infiltration and produces the greatest degree of hemostasis. Approximately $1 \%$ of the aspirate is blood [12].

No blood transfusion was needed postoperatively for any of our cases. Paul et al., performed total body contouring with mega-liposuction of 8 liters and more on 120 consecutive cases. The authors found no need for blood transfusion [13].

The decision of the volume of fats to be removed in mega liposuction is very tricky and need great caution to prevent the hazardous effects of hypervolemia and other adverse events of mega liposuction. Thus we decided to study how the usage of continuous noninvasive hemoglobin meas- urements intraoperative as a surrogate marker to help decide when to stop the liposuction. We used the validated noninvasive hemoglobin measurements using the Masimo Radical-7 device [14]. Noninvasive hemoglobin monitoring is a new technology that correlated with laboratory values and supported the continued study of noninvasive hemoglobin monitoring [14].

The results of the current case-series study showed that the majority of patients were female. All patients were obese. Mild anemia was encountered intraoperative in some patients and postoperative in the majority of them. However, none suffered moderate to severe anemia.

The results of our study showed that the usage of intraoperative noninvasive continuous measurements of HB level by the Masimo Radical-7 SpHb Station (Masimo Corporation, Irvine, CA) is very beneficial to monitor the HB level on-table and helped to detect when to stop the liposuction.

Finally, we believe that this proposed novel method with its maintained success in those types of patients is a reliable option than can be considered as it is a simple, rather effective and competent method to optimize the results of the mega liposuction operations.

\section{Conclusion:}

In this case series, we can conclude that noninvasive hemoglobin monitoring during meg liposuction has been demonstrated to be a reliable method to help decide when to sopt the operation or at which amount of fat volume removed should we stop in each patient.

\section{Declaration of interest:}

All authors declare that no conflict of interest could be perceived as prejudicing the impartiality of the research reported.

\section{Funding:}

This research did not receive any specific grant from any funding agency in the public, commercial or not-for-profit sector.

\section{REFERENCES}

1- Kopelman P.G.: Obesity as a medical problem. Nature, 404: 635-43, 2000

2- Evstatiev D. and Boichev B.: Liposuction in outpatient/oneday surgery. Khirurgiia (Sofiia), 60 (6): 13-5, 2004.

3- American Society for Plastic Surgery. Information on statistics. Available at www.plasticsurgery.org. Accessed June, 2007. 
4- Cardenas-Camarena C.L., Tobar-Losada A. and Lacouture A.M.: Large volume circumferential liposuction with tumescent technique: A sure and viable procedure. Plast. Reconstr. Surg., 104 (6): 1887-99, 1999.

5- Iverson R.E. and Lynch M.D.: The ASPS Committee on Patient Safety. Practice advisory on liposuction. Plast. Reconstr. Surg., 113: 1478-1485, 2004.

6- Lipoplasty (Press Release): Arlington Heights, Ill.: American Society of Plastic and Reconstructive Surgeons and the Plastic Surgery Educational Foundation, February 9, 1998.

7- Hanke C.W. and Coleman W.P. III: Morbidity and mortality related to liposuction: Questions and answers. Dermatol. Clin., 17: 899, 1999.

8- Trott S.A., Beran S.J., Rohrich R.J., et al.: Safety considerations and fluid resuscitation in liposuction: An analysis of 53 consecutive patients. Plast. Reconstr. Surg., 102: $2220-2229,1998$.

9- Rao R.B., Ely S.F. and Hoffman R.S.: Deaths related to liposuction. N. Engl. J. Med., 340: 1471, 1999.
10- Albin R. and de Campo T.: Large-volume liposuction in 181 patients. Aesthetic. Plast. Surg., 23: 5-15, 1999.

11- Commons G.W., Halperin B. and Chang CC.: Largevolume liposuction: A review of 631 consecutive cases over 12 years. Plast. Reconstr. Surg., 108: 1753-1763, 2001.

12- Maxwell G.P. and Gingrass M.K.: Ultrasound-assisted lipoplasty: A clinical study of 250 consecutive patients. Plast. Reconstr. Surg., 101: 189. View Article Pub Med. Google Scholar, 1998.

13- Alegría Paul, Barba Julio and Guerrero-Santos José: Total corporal contouring with mega-liposuction (120 consecutive cases) Aesth. Plast Surg., 23: 93-100. Google Scholar, 1999.

14- Causey M.W.1., Miller S., Foster A., Beekley A., Zenger D. and Martin M.: Validation of noninvasive hemoglobin measurements using the Masimo Radical-7 SpHb Station. Am. J. Surg. May, 201 (5): 592-8. doi: 10.1016/j.amjsurg. 2011.01.020, 2011. 